Check for updates

Cite this: J. Mater. Chem. C, 2019, 7,414

Received 19th October 2018, Accepted 6th November 2018 DOI: $10.1039 / \mathrm{c} 8 \mathrm{tc} 05286 \mathrm{~g}$

rsc.li/materials-c

\section{Physical vapour deposition of cyanine salts and their first application in organic electronic devices $\dagger$}

\author{
Donatas Gesevičius, ${ }^{a b}$ Antonia Neels, (D) ${ }^{c}$ Léo Duchêne, (D) ${ }^{d}$ Erwin Hack, (D) e \\ Jakob Heier (D) *a and Frank Nüesch (iD) af
}

\begin{abstract}
A symmetrical trimethine indocyanine dye chromophore was modified with the bistriflylimide anion to study the changes in Coulomb interactions, thermal stability and the volatility of the organic salt. The bulky bistriflylimide anion minimizes electrostatic interactions and increases the vapour pressure of the compound resulting in an increased volatility of the organic salt. First examples of entirely vacuumprocessed bulk heterojunction organic photovoltaic devices show the proof of concept. We give evidence that the well dispersed negative charge of the bistriflylimide introduces quasi gas phase conditions to the cyanine chromophore. This overcomes the existing restriction of thin film formation via spincasting in cyanine dye based organic electronics and expands the thin film fabrication process choices towards physical vapour deposition.
\end{abstract}

\section{Introduction}

Organic electronic devices have an over 60 year long history of intense research. ${ }^{1,2}$ Besides the fundamental understanding of electronic processes in organic semiconductor devices, proper layer formation by suitable deposition techniques plays a crucial role in obtaining a successfully working device. In academic research wet film formation processes ${ }^{3-8}$ are most popular and especially spincasting ${ }^{9}$ is established as a fast technique to form thin films of small area. Despite its popularity, spincasting has several drawbacks such as little control over the desired film geometry. In addition, the resulting film quality strongly depends on substrate surface wetting of the

\footnotetext{
${ }^{a}$ Laboratory for Functional Polymers, Swiss Federal Laboratories for Materials Science and Technology, Empa, Überlandstrasse 129, Dübendorf, Switzerland. E-mail: jakob.heier@empa.ch

${ }^{b}$ Institute of Chemical Sciences and Engineering, ISIC, Ecole Polytechnique Fédérale de Lausanne, EPFL, Station 6, CH-1015 Lausanne, Switzerland

${ }^{c}$ Center for X-ray Analytics, Swiss Federal Laboratories for Materials Science and Technology, Empa, Überlandstrasse 129, Dübendorf, Switzerland

${ }^{d}$ Laboratory Materials for Energy Conversion, Swiss Federal Laboratories for Materials Science and Technology, Empa, Überlandstrasse 129, Dübendorf, Switzerland

${ }^{e}$ Laboratory for Transport at Nanoscale Interfaces, Swiss Federal Laboratories for Materials Science and Technology, Empa, Überlandstrasse 129, Dübendorf, Switzerland

${ }^{f}$ Institut des Matériaux, Ecole Polytechnique Fédérale de Lausanne, EPFL, Station 6, CH-1015 Lausanne, Switzerland

$\dagger$ Electronic supplementary information (ESI) available. CCDC 1834037 and 1834038. For ESI and crystallographic data in CIF or other electronic format see DOI: $10.1039 / \mathrm{c} 8 \mathrm{tc} 05286 \mathrm{~g}$
}

solution. Organic electronic devices in research often consist of several thin layers with similar solubility, making fabrication of a multistack device via spincasting a challenging task. However, industry requires large area homogenous thin film layers, high precision in geometry control and long term stability, which are usually achieved by vacuum deposition techniques. ${ }^{8,10-15}$

The majority of small molecule organic semiconductors are neutral. ${ }^{16}$ However, indolenium-cyanine dyes belong to the class of organic salts, with the characteristic presence of an electron accepting quaternary ammonia group (antiauxochrome) as well as an electron donating ternary amino moiety (auxochrome) which are connected via a polymethine chain. Such a geometry creates a fully delocalised charge over the polymethine backbone within the cyanine limit and enables many of their attractive optical properties, such as large extinction coefficients. ${ }^{17-19}$ Since their discovery in $1856^{20}$ cyanine dyes were used in various applications, according to the scientific interest in each decade starting from photography, ${ }^{20} \mathrm{CD}-\mathrm{R}$ based data storage, ${ }^{21-24}$ life science, ${ }^{25,26}$ non-linear optics ${ }^{27,28}$ and organic photovoltaics (OPV) or photodiodes. ${ }^{17,29-39}$

While neutral organic semiconductors can be easily evaporated mainly due to the weak intermolecular van der Waals forces, ionic organic functional materials such as cyanine dyes suffer from strong Coulomb interactions which results in high melting points and decomposition at ambient temperatures. ${ }^{40,41}$ Heteroatoms in the polymethine chain or in aromatic moieties as well as high molecular weight of the cyanine salts and counterions with localised charge induce additional decomposition pathways when thermal stress is applied. ${ }^{24}$ These drawbacks prevented 
successful implementation of physical vapour deposition techniques in cyanine dye based semiconductor research.

Weakly coordinating anions as the key to improve both chromophore stability in the excited state and organic electronic device performance are emerging topics. ${ }^{37,42}$ The influence of a weakly coordinating anion on the volatility of the cyanine salts was not reported in the literature so far. Our work presents guidelines for a successful design of evaporable cyanine organic salts with the aim to open future research possibilities regarding the synthesis of evaporable cyanine salts, organic electronic device fabrication and optimisation as well as theoretical calculations on new emerging thermodynamic properties. Besides the fundamental interest in overcoming present limitations and making a cyanine salt thermally stable but volatile enough to be evaporated before decomposition occurs, we demonstrate first applications in organic electronic devices where thin film formation had taken place by a physical vapour deposition based fabrication method.

\section{Results and discussion}

\subsection{From material synthesis to optical and electrochemical properties}

The bistriflylimide (TFSI) anion was introduced into 1-ethyl-2[3-(1-ethyl-1,3-dihydro-3,3-dimethyl-2H-indol-2-ylidene)-1-propen1-yl]-3,3-dimethyl-3H-indolium iodide (Cy3I), exchanging the partially redox active iodide anion from the starting material by using an Amberlyst ${ }^{\circledR}$ A26 $\left(\mathrm{OH}^{-}\right.$form) wet anion exchange resin. The detailed working principles and experimental setup were reported elsewhere. ${ }^{42}$ For simplicity the dye shall be denoted as Cy3TFSI (Fig. 1 and Fig. S1, ESI $\dagger$ ) in the following.

Four different substrates were chosen and compared to the solution spectrum to investigate the UV-vis properties of vapour deposited Cy3TFSI films with respect to further application in organic electronic devices (Fig. 1 and Fig. S2, ESI $\dagger$ ). Cy3TFSI has an absorbance maximum in acetonitrile solution attributed to the $0 \rightarrow 0$ transition at $544 \mathrm{~nm}$ with a shoulder shifted by
$1182 \mathrm{~cm}^{-1}$ towards shorter wavelengths at $512 \mathrm{~nm}$ due to a dominant vibronic mode resulting from the $0 \rightarrow 1$ or $0 \rightarrow 2$ transition. The absorbance peak spans a range between 455 and $567 \mathrm{~nm}$. With a relative molar extinction coefficient of $2.40 \times 10^{5} \mathrm{~L} \mathrm{~mol}^{-1} \mathrm{~cm}^{-1}$ in acetonitrile solution the dye manifests strong light absorption which is most beneficial to light harvesting in thin films as required for OPV devices (Fig. S3 and Table S1, ESI $\dagger$ ). Depending on the substrate used the solid state absorbance broadens up to $1302 \mathrm{~cm}^{-1}$ for glass, $2269 \mathrm{~cm}^{-1}$ for $\mathrm{MoO}_{3}, 3401 \mathrm{~cm}^{-1}$ for PEDOT:PSS and $4371 \mathrm{~cm}^{-1}$ for mesoporous $\mathrm{TiO}_{2}$. The blue shifted shoulder grows and becomes a dominant species on $\mathrm{TiO}_{2}\left(1366 \mathrm{~cm}^{-1}\right)$ and $\mathrm{MoO}_{3}$ $\left(1496 \mathrm{~cm}^{-1}\right)$ substrates with a measured ratio of $1: 0.91$ and 1:0.87 respectively. The opposite effect is observed on glass with a shift of $1531 \mathrm{~cm}^{-1}$ and PEDOT:PSS $\left(1405 \mathrm{~cm}^{-1}\right)$ showing a ratio between the shoulder and the main peak of $0.92: 1$ and $0.7: 1$, respectively. Such differences in peak/shoulder ratios, absorbance peak shapes and shoulder shifts indicate differences in the thin film morphology. A film with large thickness variations could cause the observed peak broadening in the UV-vis spectrum due to geometrical reasons and points either towards dewetted or rough surfaces. Dimerization and aggregation effects induced by solid state packing of the molecules could contribute as well to shoulder formation at shorter wavelengths. In general the optical properties of vapour deposited molecules are similar to those of spin cast films. ${ }^{43}$

The Cy3TFSI dye belongs to the class of intermediate band gap semiconductors possessing an electrochemical energy gap of $1.86 \mathrm{eV}$ with intermediate electron affinity and high positive oxidation potential (Fig. S4 and Table S4, ESI $\dagger$ ). The TFSI anion is not redox active within the electrochemical window of the chromophore. Fig. 1 depicts the relative energy levels of the possible organic electronic device interlayers. With a HOMO of $-5.71 \mathrm{eV}$ and a LUMO of $-3.85 \mathrm{eV}$, Cy3TFSI can be employed as an electron donor in both standard geometry with the hole collecting layer on the substrate anode as well as in inverted geometry with the electron collecting layer on the substrate cathode.
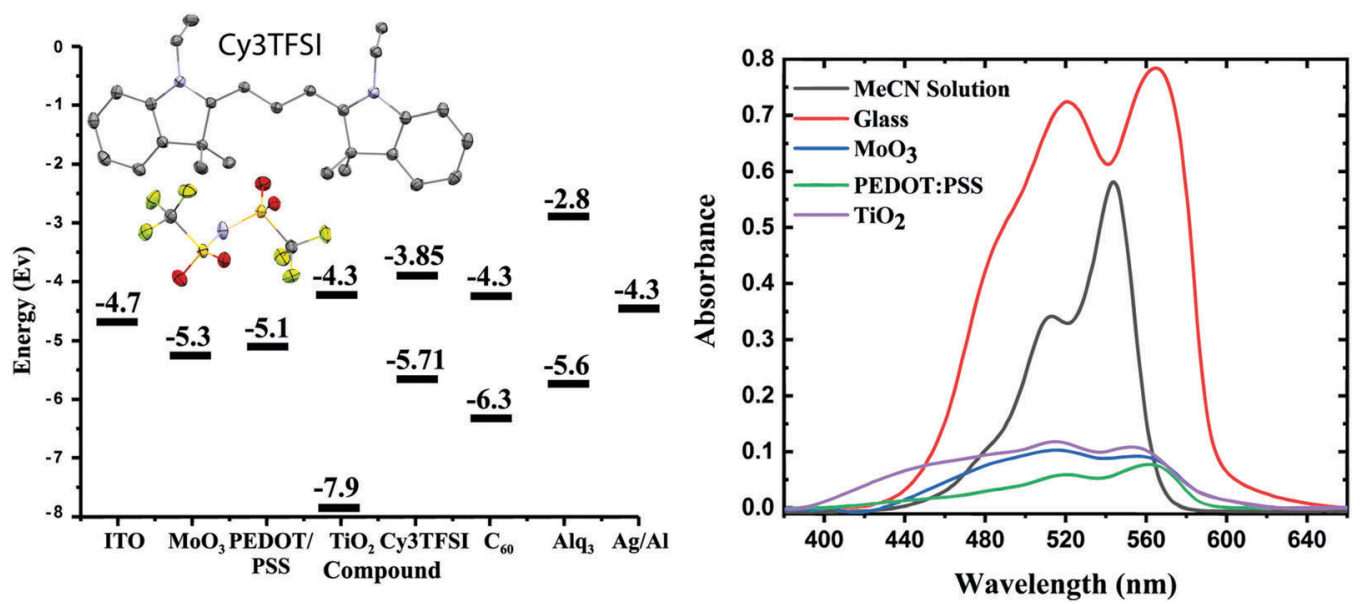

Fig. 1 On the left: Cartoon depicting the molecular structure of the Cy3TFSI salt with the corresponding energy level alignment respective possible device fabrication. On the right: Qualitative UV-vis spectra of evaporated thin films on different substrates. The films have different average thicknesses. 


\subsection{Factors enabling physical vapour deposition}

Physical vapour deposition under vacuum occurs either by sublimation of a solid or by evaporation of a molten substance. Which process takes place is determined by the triple point of the compound. Both mechanisms require a high thermal stability of the compounds. The combined methods of thermogravimetric analysis (TGA) and differential scanning calorimetry (DSC) reveal a melt based evaporation process for the Cy3TFSI dye (Fig. 2). Considering the melting peak onset values, Cy3TFSI has a melting point of $156{ }^{\circ} \mathrm{C}$ compared to $165{ }^{\circ} \mathrm{C}$ observed for the starting material. Despite the larger molecular weight of Cy3TFSI, the melting point is lowered by $10{ }^{\circ} \mathrm{C}$ proving that the bulky anion with its dispersed negative charge reduces intermolecular chromophore interactions. Similar findings regarding the influence of Coulomb interactions on ion pair evaporation were mentioned in the literature on ionic liquids. ${ }^{44}$ Significant $2 \%$ mass losses were obtained at $280{ }^{\circ} \mathrm{C}$ for Cy3TFSI while the starting material reaches this onset already at $252{ }^{\circ} \mathrm{C}$. A low melting point and an increased thermal stability favour successful evaporation of an organic salt by widening the thermal window until the decomposition temperature is reached. However, the thermal degradation mechanism is not trivial as it is not sufficient to assign an initial mass loss to its decomposition point, especially for a volatile compound. Additionally, the literature on ionic liquids points towards significant differences in mass loss mechanisms driven either by vaporisation or decomposition or even simultaneous occurrence of both depending on ultra-high vacuum (UHV), high vacuum (HV) or ambient pressure conditions. ${ }^{45}$ Despite material class differences and a different focus of this work we try to adopt some of the experiments from the literature and reveal first insights into the evaporation mechanism of cyanine salts. While the starting material shows a two-step mass loss in dynamic TGA (Fig. 2) with relative integrals of 46 and $42 \%$ up to the range of $450{ }^{\circ} \mathrm{C}$ and two endothermal peaks at 265 and $283{ }^{\circ} \mathrm{C}$ (peak maxima) in the DSC suggesting a two-step degradation, Cy3TFSI has a more complex TGA curve (Fig. 2). Three well distinguished steps can be identified with relative integrals of 19,26 and $42 \%$ accompanied by a sharp exothermal DSC peak at $285{ }^{\circ} \mathrm{C}$ (peak maximum).
Evidence that the evaporated Cy3TFSI that comes to rest on the substrate and the starting material are identical is given by UV-vis spectroscopy. The solution spectrum of a re-dissolved film matches the solution spectra of the starting material. Differently, with Cy3I also the half-dye is observed (Fig. S5, ESI $\dagger$ ).

The information content of a dynamic TGA measurement is limited regarding the evaporation mechanism of a compound. To extract the enthalpy of vaporisation $\left(\Delta_{1}^{\mathrm{g}} H_{\mathrm{m}}^{\circ}\left(T_{\mathrm{av}}\right)\right)$ at an average temperature as a physical value describing the evaporation process, a quasi-isothermal TGA measurement was performed (ESI, $\dagger$ Thermal behaviour section). ${ }^{46}$ Fig. 3 and Fig. S6 and S7 (ESI $\dagger$ ) display the differences in mass loss of each isothermal step for Cy3I and Cy3TFSI. An evaporation process is expected to have a defined vapour pressure at a given temperature and thus behaves linearly over time while decomposition should occur spontaneously with inconsistent vapour pressure showing a non-linear mass loss over time. The extracted slopes of the isothermal weight loss behave nonlinearly for both materials as a function of temperature. Cy3TFSI possesses a wide linear region from $220-250{ }^{\circ} \mathrm{C}$ which can be attributed to the evaporation process. The exponential increase in mass loss of the starting material can be attributed to the simultaneous occurrence of partial evaporation and decomposition mainly visible from the UV-vis spectra of, respectively, heated samples at a particular temperature (Fig. S8, ESI $\dagger$ ). Approaching a temperature range above $250{ }^{\circ} \mathrm{C}$ both materials show a DSC activity. With the exothermal DSC peak onset at $269{ }^{\circ} \mathrm{C}$ for Cy3TFSI the mass loss decreases sharply reaching a local minimum at $270{ }^{\circ} \mathrm{C}$ pointing towards partial decomposition forming non-volatile degradation products as visible in the UV-vis spectrum (Fig. S8, ESI $\dagger$ ). The unpredictable mass loss decrease over time especially during isothermal steps at 250 and $260{ }^{\circ} \mathrm{C}$ with the corresponding broad endothermal DSC peak onset at $260{ }^{\circ} \mathrm{C}$ and random distribution of $\mathrm{d} m / \mathrm{d} t v s$. $T$ indicate that Cy3I undergoes unpredictable thermal decomposition only (Fig. 3 and Fig. S6-S8, ESI $\dagger$ ). The decomposition only pathway is supported by observing a $75 \%$ total weight loss for Cy3I compared to only $27 \%$ obtained for Cy3TFSI during the measurement. This points towards the assumption that Cy3I forms volatile decomposition species while Cy3TFSI is more
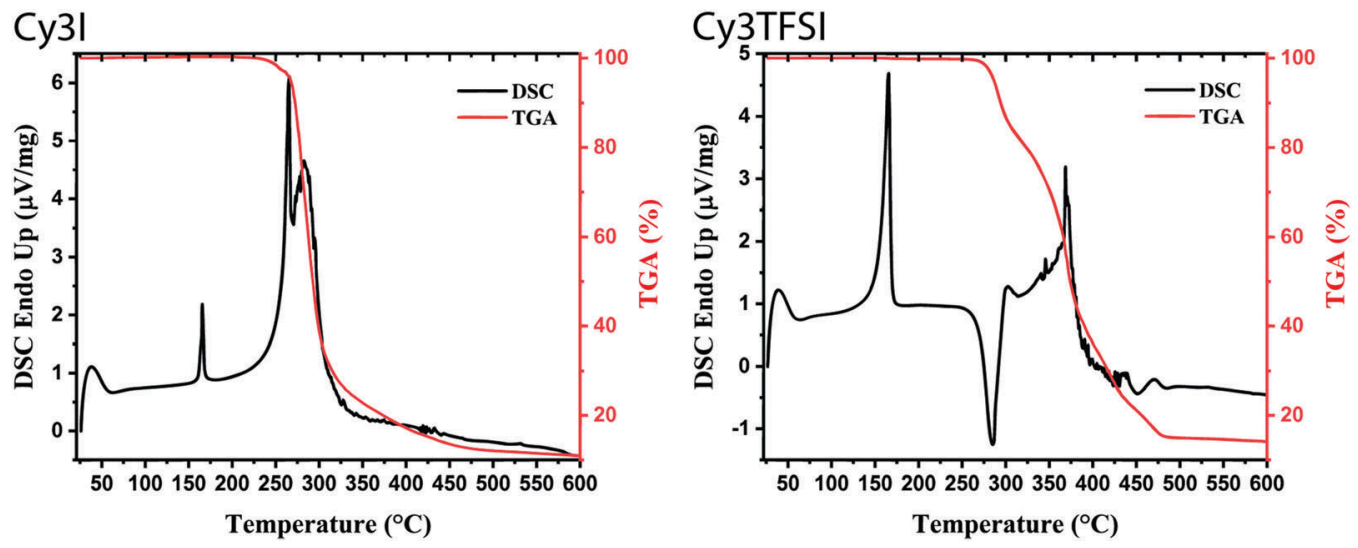

Fig. 2 Dynamic TGA $\left(10^{\circ} \mathrm{C} \mathrm{min}^{-1}\right)$ with the corresponding DSC signal of starting material (Cy3l) and Cy3TFSI. 
СузІ
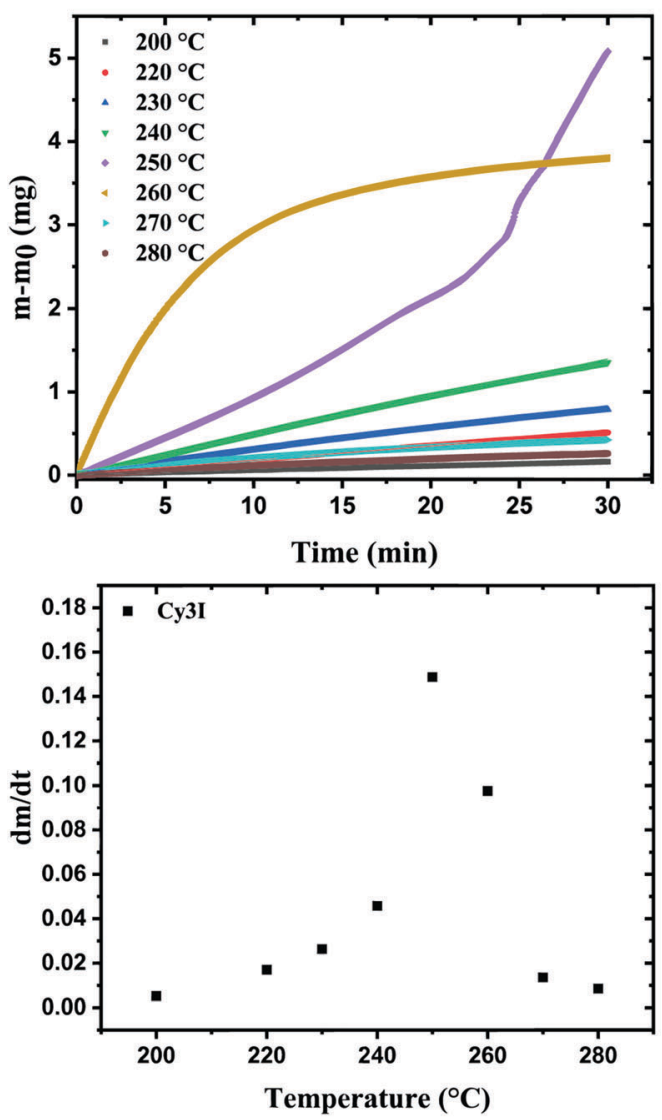

Cy3TFSI
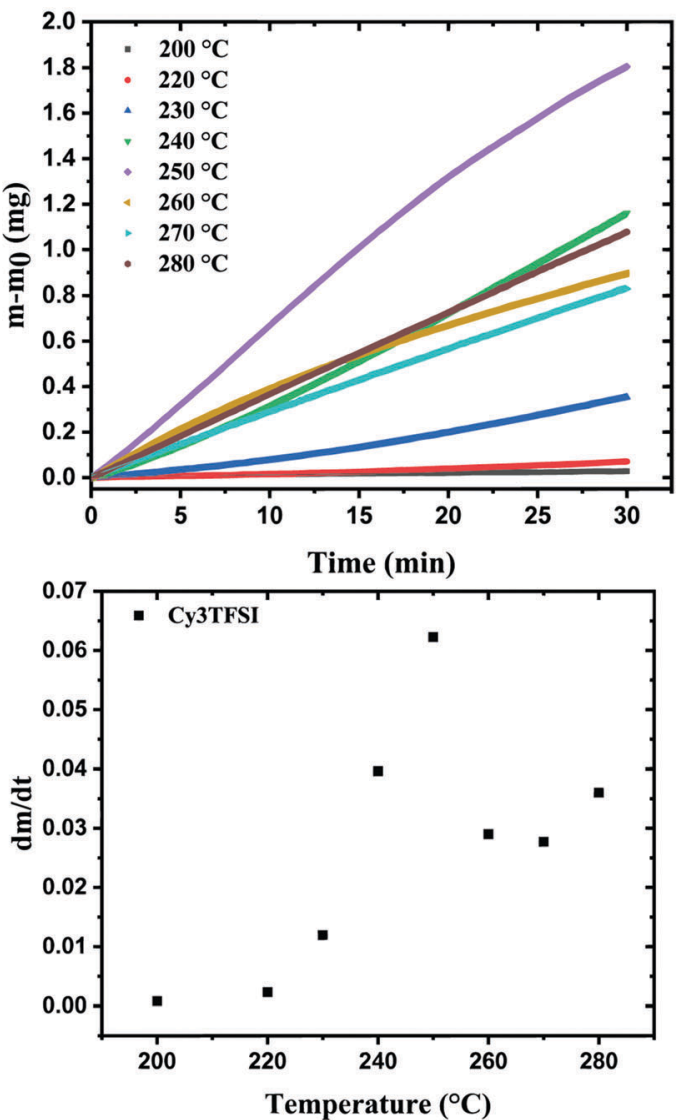

Fig. 3 The upper row represents extracted weight losses as a function of time occurring during each isothermal step. The lower row represents the extracted slopes of the isothermal weight loss curves as a function of temperature.

stable and decomposes only partially by forming less volatile decomposition species.

Applying the developed model for ionic liquids we obtain a value for $\Delta_{1}^{\mathrm{g}} H_{\mathrm{m}}^{\circ}\left(T_{\mathrm{av}}\right)$ of $152.8 \mathrm{~kJ} \mathrm{~mol}^{-1}$ for Cy3TFSI within a temperature range of $220-250{ }^{\circ} \mathrm{C}$ (Tables S5-S7 and Fig. S9, ESI $\dagger$ ). ${ }^{46}$ With this approach we provide first experimental results quantifying the thermal evaporation process of Cy3TFSI which will be helpful in deeper future thermodynamic investigations.

In summary it can be concluded that the literature of thermogravimetric experiments of cyanine dyes has to be revised. The thermal behaviour of cyanine dyes containing weakly coordinating anions is more complicated than assigning the first significant mass loss to a decomposition temperature. Furthermore, the thermal behaviour under ambient pressure may strongly deviate from the conditions inside a HV evaporation chamber, making conclusions even more complex.

The thermal properties of an organic salt are closely linked to its molecular packing as well as with the strength of electrostatic interactions in the solid state. Therefore we link the crystal structures of Cy3TFSI and Cy3I to the physical vapour deposition phenomenon and define the lattice energy as a key parameter. Single crystals were obtained by cooling saturated ethanol solutions. The starting material crystallizes in a monoclinic lattice with the space group $P 2_{1} / c$ while Cy3TFSI belongs to the orthorhombic system with the $P 2_{1} 2_{1} 2_{1}$ space group. The shortest observed anion coordination distances of $7.65 \AA$ for Cy3TFSI and $5.07 \AA$ for Cy3I in Fig. 4 give qualitative insights into reduced electrostatic interactions within Cy3TFSI. Relative lattice energies of $359.09 \mathrm{~kJ} \mathrm{~mol}^{-1}$ for Cy3TFSI and $376.93 \mathrm{~kJ} \mathrm{~mol}^{-1}$ for Cy3I and the Coulomb interactions of $0.67 \mathrm{eV}$ for Cy3TFSI and $0.77 \mathrm{eV}$ for Cy3I, respectively, were estimated according to a literature method (Tables S8 and S9, ESI $\dagger$ ). ${ }^{47}$ The estimated lattice and Coulomb energy values are well below the ones obtained for inorganic molecular ions as well as smaller organic ionic liquids and visualise well the strong influence of the bulky bistriflylimide on the thermal stability of the Cy3TFSI chromophore.

The bistriflylimide anion prevents short distance intermolecular chromophore interactions since no regular packing motif can be observed (Fig. 5). In contrast the chromophores in Cy3I are packed in two symmetry equivalents; see Fig. 5: the blue layers form a plane that sandwiches the cross bone packed yellow symmetry equivalent layer. The iodide anions are closely distributed along the plane of blue chromophores pointing 

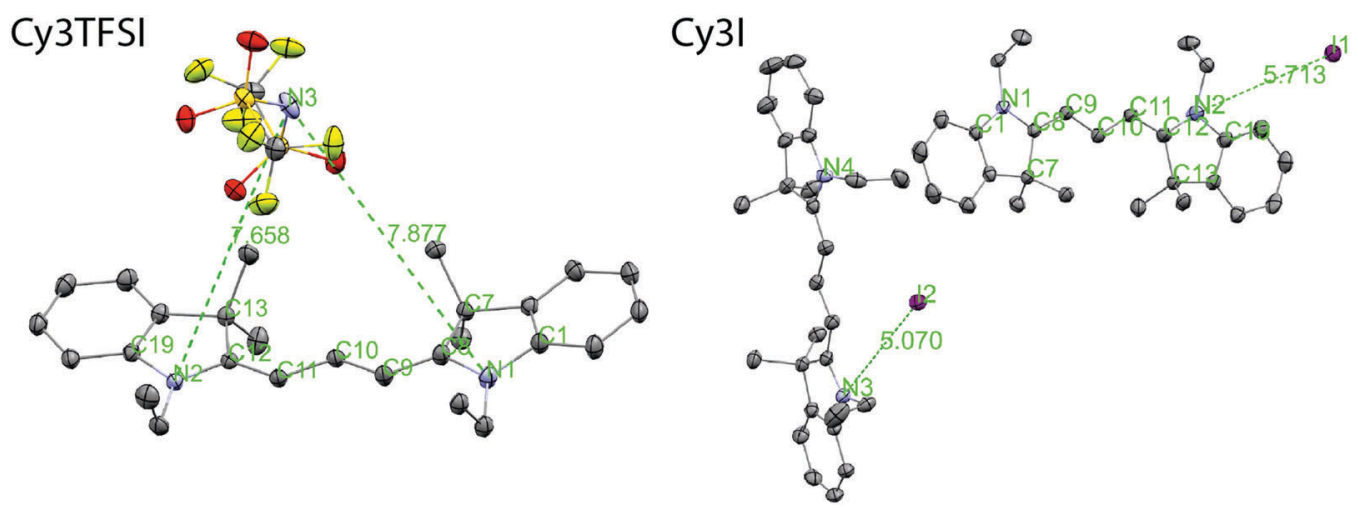

Fig. 4 Molecular structure and anion coordination environment observed in the single crystal structures of Cy3I and Cy3TFSI. The shortest anionchromophore distances are given in $\AA$. The thermal ellipsoids represent $50 \%$ probability levels. The disorder in Cy3TFSI as well as the hydrogen atoms are omitted for clarity. Color code: C: grey, N: violet, S: yellow, O: red, F: yellow-green, I: purple.

\section{Cy3TFSI}
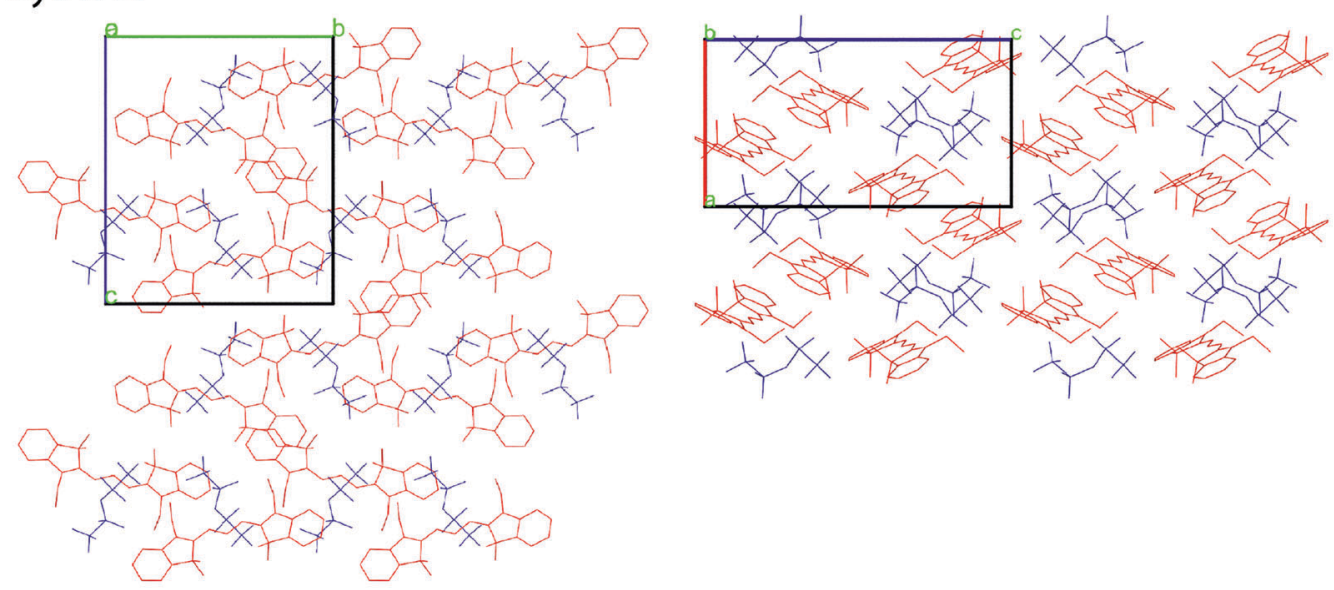

\section{СузІ}
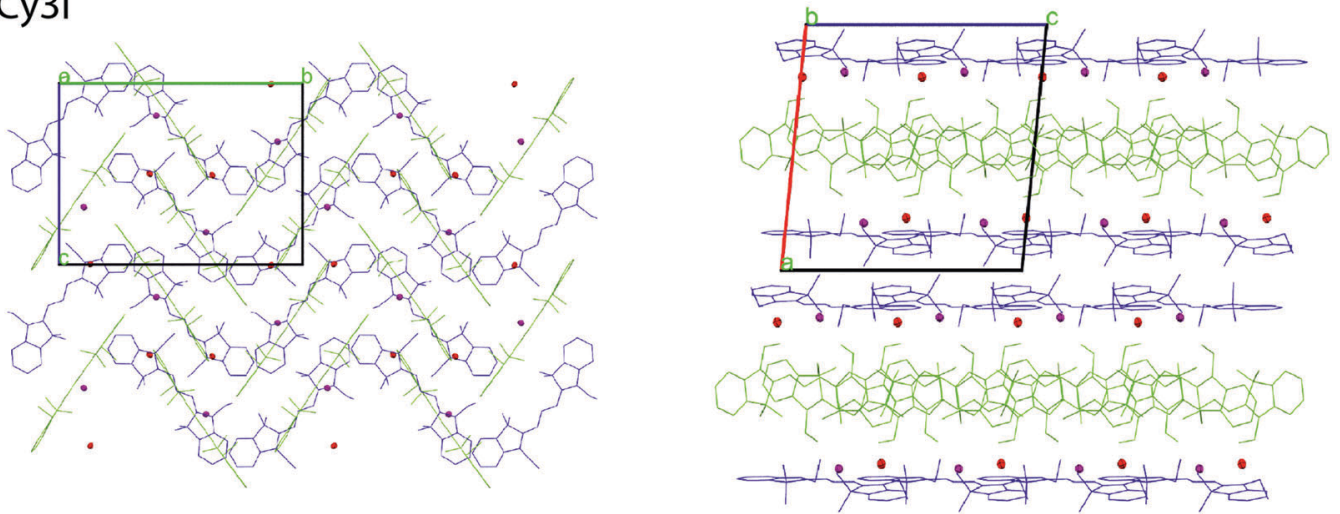

Fig. 5 Molecular arrangement over $2 \times 2 \times 2$ unit cells with views along the $a$ axis (left) and $b$ axis (right). For clarity the Cy3TFSI packing is depicted in the wire frame model, while Cy3l contains the chromophore in the wire frame and the iodide as a thermal ellipsoid with a $50 \%$ probability level. The disorder in Cy3TFSI as well as the hydrogen atoms are omitted for clarity. Color code: Cy3TFSI symmetry equivalent chromophores: red, anion: blue. Cy3l symmetry equivalent chromophores: blue and green, iodide: red or purple.

towards complex shared anion-cation interactions within the two symmetry operation separated layers as observed by the highly asymmetric iodide-chromophore coordination distance (Fig. 4). Despite the well-ordered symmetry close $\pi$-stacking or long range heteroatom interactions are prevented, since the closest chromophore distances exceed $5 \AA$. The packing motifs are in agreement with the $10{ }^{\circ} \mathrm{C}$ difference in the melting point between Cy3TFSI and Cy3I. 


\subsection{Substrate dependent thin film morphology}

The concept of "physical vapour deposited cyanine organic electronics" was proven in devices with standard geometry containing hole transport layers such as $\mathrm{MoO}_{3}$ or PEDOT:PSS as well as inverted geometry devices with compact and mesoporous $\mathrm{TiO}_{2}$, using commercially available indium-tin-oxide (ITO) on glass as a substrate. Thin film formation during vacuum deposition is mainly determined by the surface energy of the substrate, substrate temperature and the evaporation rate which allows the formulation of different growth mechanisms. ${ }^{48}$ Depending on the substrate used, significantly different morphologies of the Cy3TFSI dye were obtained (Fig. 6). The glass substrate leads to the formation of well isolated up to 2 micrometre sized islands of $70 \mathrm{~nm}$ height (Fig. S14, ESI $\dagger$ ). It provides also the roughest surface of the investigated thin films, such droplet formation results from dewetting phenomena. $\mathrm{MoO}_{3}$ provides a better surface energy match by firstly adsorbing a thin dye layer followed by an irregularly shaped micrometre sized island formation indicating possible continuous film formation at higher thicknesses but with increased surface roughness comparable to a mechanism formulated by Stranski-Krastanov. ${ }^{48}$ When PEDOT:PSS is employed, the amorphous film with low overall surface roughness forms over areas of more than $10 \mu \mathrm{m}^{2}$. However, on a larger scale dewetting holes up to $6 \mu \mathrm{m}$ in diameter (Fig. S14, ESI $\dagger$ ) as well as local dye droplet formation on the amorphous bottom layer is observed, indicating an additional abrupt organic material erosion from the crucible. The high surface energy mismatch can be bypassed when naturally rough mesoporous $\mathrm{TiO}_{2}$ with large surface volume is used. The atomic force microscopy (AFM) scanned area reveals spherical particles smaller than $500 \mathrm{~nm}$ in diameter close to native mesoporous $\mathrm{TiO}_{2}$ morphology suggesting a continuous dye coverage of the $\mathrm{TiO}_{2}$ particles. Together with $\mathrm{MoO}_{3}$ the investigated dye film on mesoporous $\mathrm{TiO}_{2}$ provides the smallest surface roughness (Fig. S14, ESI $\dagger$ ).
We can assume that the films formed after the melt based evaporation are amorphous in nature. In this sense our evaporation process is different from a sublimation process. Neither AFM nor UV-vis spectroscopy points to the presence of crystalline domains.

We here also want to point to a drawback of films processed from solution. We had observed earlier that these films contain considerable amounts of residual solvents. ${ }^{49}$ This leads to increased mobility of dye molecules and may account for the ability of the molecules in the film to crystallize over time. We also demonstrated that the solvent molecules have a significant influence on electronic processes at interfaces in solar cells.

Further trials to form a bulk heterojunction by co-evaporation of Cy3TFSI and fullerene $\mathrm{C}_{60}$ blends on $\mathrm{MoO}_{3}$ and compact $\mathrm{TiO}_{2}$ substrates (Fig. 7) have led to a better surface energy match. The surface roughness in the order of $2 \mathrm{~nm}$ in both blends is low and should allow applications in either standard or inverted geometry bulk heterojunction devices. The surface profile exhibits mixed random amorphous features suggesting suppressed phase separation below $1 \mu \mathrm{m}$ in diameter. A spinodal pattern is recognisable on the $\mathrm{TiO}_{2}$ substrate. However, local organic material accumulation ascending several nanometres from the surface can also be observed in both blends, mainly caused by an abrupt Cy3TFSI ejection from the crucible.

Solution processed blend films of cyanine dyes and fullerenes on the other hand frequently phase separate into large scale structures by liquid-liquid dewetting. ${ }^{50}$ Here co-evaporating Cy3TFSI and a fullerene leads to a more favourable morphology for solar cell application than the spincoated samples (see Section 4.2. Device fabrication).

In summary, wetting phenomena observed during spincasting from solution also apply to evaporated cyanine films making extended film tuning on different substrates an important issue. The substrate coverage can be improved by blending Cy3TFSI or incorporating it as a dopant into a carrier matrix for OLED application overcoming the surface energy mismatch.
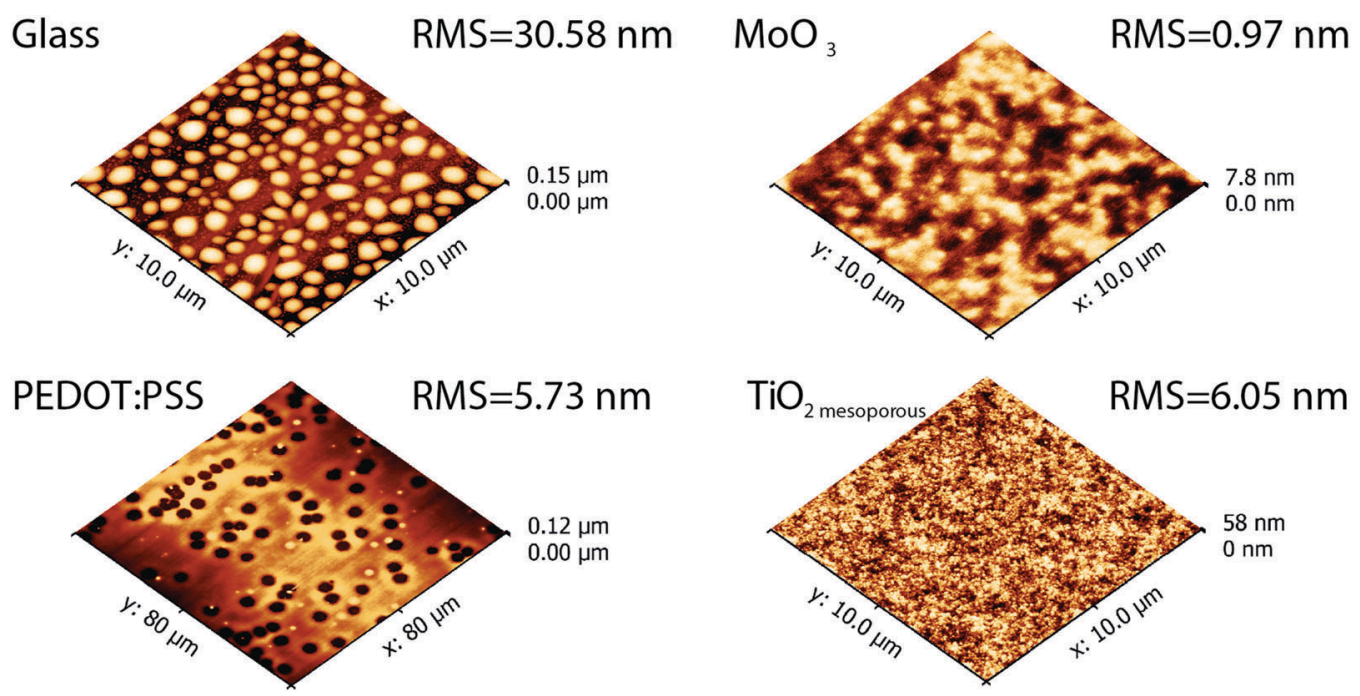

Fig. 6 Topography of vacuum deposited Cy3TFSI films on different substrates. 

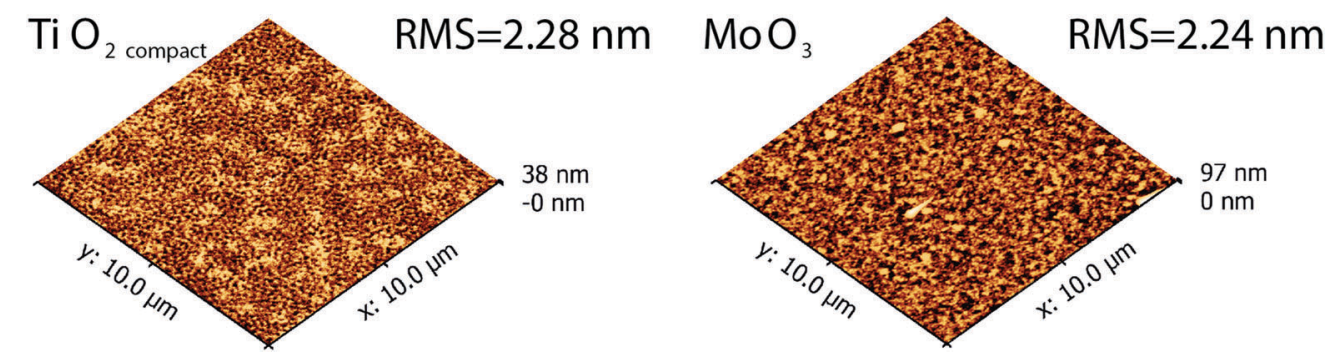

Fig. 7 Topography of co-evaporated Cy3TFSI and $\mathrm{C}_{60}$ on $\mathrm{TiO}_{2}$ and $\mathrm{MoO}_{3}$ substrates.

\subsection{Proof of concept in organic electronic devices}

The Cy3TFSI salt enables a wide variety of electronic device fabrication methods not seen in cyanine dye semiconductors so far. First proof-of-concept devices are presented with pros and cons regarding their further perspectives. With an open circuit voltage of $1 \mathrm{~V}$, a solution based bilayer device of Cy3TFSI and $\mathrm{C}_{60}$ shows one of the highest potentials among all organic semiconductors (Table S13, ESI $\dagger$ ). One of the major existing limitations in cyanine dye semiconductors for organic photovoltaic applications was the so far only poorly performing bulk-heterojunction morphology. ${ }^{51}$ By blending cyanine dyes with fullerene based electron acceptors in solution, typically micrometre sized phase separated domains of pure cyanine/ fullerene rich phases form as demonstrated in Fig. S15 (ESI $\dagger$ ). Such a morphology leads to short circuited organic photovoltaic devices (Table S14, ESI $\dagger$ ). However our new approach of simultaneous dye/fullerene evaporation has led to the first vacuum processed cyanine dye based bulk heterojunction device.

Cy3TFSI was employed as an electron donor material in a fully vacuum processed inverted geometry bulk heterojunction OPV device. In total 32 cells with 8 cells per substrate were prepared. 13 cells showed short circuit behaviour, therefore 19 cells could be measured. Fig. 8 represents the best performing device of the batch. The OPV device exhibits a dark current of $0.34 \mathrm{~mA} \mathrm{~cm}^{-2}$ at $-0.8 \mathrm{~V}$. One origin of the dark current could be alternative pathways through the thin active layer formed by a continuous electron acceptor channel ranging from the hole collecting layer to $\mathrm{TiO}_{2}$. This could partially explain the relative low fill factor $(\mathrm{FF})$ of $41.5 \%$ and the open circuit voltage $\left(V_{\mathrm{oc}}\right)$ of $0.67 \mathrm{~V}$ in the device. The relatively low $V_{\text {oc }}$ points also towards the not optimal morphology of the active layer missing the well-defined phase separated networks between the dye and electron acceptor in the order of 10-20 nm. The AFM analysis in Fig. 7 shows the absence of micrometre sized phase separated domains in freshly prepared blends, which typically would occur when cyanine dye fullerene blends are coated from solution. However, a repeated measurement after 3 weeks of storage in the glovebox shows several micrometre sized dendritic crystals (Fig. S16, ESI $\dagger$ ) pointing towards ongoing kinetic processes, driven by dye crystallization in the blend.

Cy3TFSI proves itself as a strong absorber capable of generating a sufficient short circuit current density $\left(J_{\mathrm{sc}}\right)$ of $4.02 \mathrm{~mA} \mathrm{~cm}^{-2}$ since an active layer thickness of only $10 \mathrm{~nm}$ is used. The values lead to a champion performance $(\eta)$ of $0.96 \%$. However, the experimentally obtained $J_{\mathrm{sc}}$ for the best device does not match the calculated $J_{\mathrm{sc}}$ of $0.90 \mathrm{~mA} \mathrm{~cm}{ }^{-2}$ from the external quantum efficiency (EQE) spectrum. This deviation originates mainly from differences in the two measurements and can only be compared when no light intensity related effects play a role. In fact, while the average $V_{\text {oc }}$ of $0.63 \pm$ $0.06 \mathrm{~V}$ and $\mathrm{FF}$ of $38.98 \pm 2.41 \%$ are stable for all 19 cells, the $J_{\mathrm{sc}}$ of $1.46 \pm 0.98 \mathrm{~mA} \mathrm{~cm}{ }^{-2}$ shows a large variation between minima and maxima. The $J_{\mathrm{sc}}$ calculated from the EQE spectrum matches the measured average value much better, pointing towards quick degradation mechanisms within the best cell.
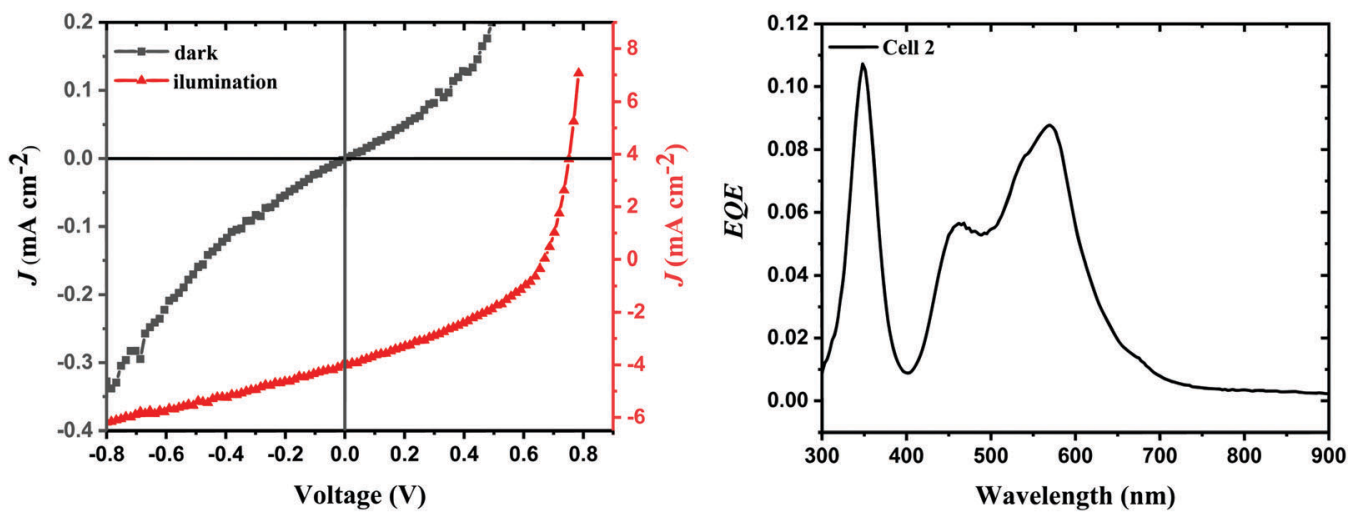

Fig. $8 \mathrm{JV}$ and EQE curves of the best performing OPV cell. The EQE represents a sharp $\mathrm{C}_{60}$ peak at shorter wavelengths followed by an overlap of the second $\mathrm{C}_{60}$ absorption peak with Cy3TFSI. 
This effect also leads to a broad distribution in an average device performance of $0.36 \pm 0.25 \%$. The EQE data prove that both components of the blend, Cy3TFSI and $\mathrm{C}_{60}$, contribute to the photovoltaic effect with an external quantum efficiency of $8 \%$. The contribution of the dye to the external quantum efficiency, however, is less than that of $\mathrm{C}_{60}$ suggesting either an extraction barrier for holes formed at the heterojunction/ $\mathrm{MoO}_{3}$ surface or a partial chromophore degradation or is simply the result of the very thin active layer used. Furthermore, the co-evaporation of Cy3TFSI and $\mathrm{C}_{60}$ prevents aggregate formation of the cyanine dye since a peak/shoulder ratio of 1:0.55 is comparable to the one obtained from acetonitrile solution although the absorbance of $\mathrm{C}_{60}$ may overlap with the shoulder at shorter wavelengths of Cy3TFSI.

Further vacuum processed devices should demonstrate the introduced flexibility by Cy3TFSI in fabricating varying device stacks. The bilayer geometry cells realized by physical vapour deposition suffer from bad morphology of the neat evaporated films as discussed in Fig. 6. A further promising device stack is the inverted bilayer cell (Fig. S17-S19 and Table S16, ESI $\dagger$ ). With a high $V_{\text {oc }}$ in the range of $0.8 \mathrm{~V}$, the inverted bilayer device approaches $V_{\text {oc }}$ values also found in a solution spin-cast bilayer reference device. The regular geometry bulk heterojunction device cannot compete with the implemented inverse structure. Furthermore the solid state dye sensitized solar cell approach seems to be less promising from all trials.

\section{Conclusions}

By employing the bistriflylimide anion with a well dispersed negative charge over seven atoms into the 1-ethyl-2-[3-(1-ethyl1,3-dihydro-3,3-dimethyl-2H-indol-2-ylidene)-1-propen-1-yl]-3,3dimethyl-3H-indolium chromophore we introduce volatility and thermal stability to an organic salt of high molecular weight. The properties of the solid state structure from single crystals and thermo-analytical methods were linked to reveal the evaporation mechanism of the dye. The lattice energy and enthalpy of vaporization were identified to be the key parameters of the first volatile organic cyanine salt. We give evidence that a weakly coordinating anion tailored for a specific chromophore regarding the number of atoms for dispersed negative charge can introduce quasi gas phase conditions to the chromophore. The semiconducting properties of the cyanine salt allowed its application in organic electronic devices as a light absorbing or emitting layer. The proof of concept was demonstrated by fabricating fully vacuum deposited OPV devices. This work aims to pave the way to development strategies of cyanine based volatile organic salts covering the full visible and infrared spectral absorption range.

\section{Experimental section}

\subsection{Materials and methods}

All chemicals and solvents were purchased from commercial sources (Aldrich, VWR, FEW Chemicals, Kurt J. Lesker) and used as received, unless otherwise stated. Reactions were carried out under an air atmosphere using common lab glass ware. NMR multicore spectra were recorded on a Bruker AV-400 spectrometer $\left({ }^{1} \mathrm{H}-\mathrm{NMR}: 400 \mathrm{MHz},{ }^{13} \mathrm{C}\left\{{ }^{1} \mathrm{H}\right\}\right.$-NMR: $100 \mathrm{MHz},{ }^{19} \mathrm{~F}\left\{{ }^{1} \mathrm{H}\right\}-\mathrm{NMR}$ : $377 \mathrm{MHz}$ ). Chemical shifts $(\delta)$ are reported in ppm (parts per million) with the solvent residual signal $\left({ }^{1} \mathrm{H} /{ }^{13} \mathrm{C}\left\{{ }^{1} \mathrm{H}\right\}\right.$ : 7.20/79 for $\mathrm{CDCl}_{3}$ ) as a reference. $J$ coupling constants are given in $\mathrm{Hz}$. Multiplicities are reported as singlet (s), doublet (d), triplet $(\mathrm{t})$, quartet $(\mathrm{q})$, and multiplet $(\mathrm{m})$. Elemental analysis data were obtained from the Micro Laboratory of ETH Zürich with the instrument Leco TruSpec Micro for C, H, N, S, F and O, while I was determined by ion chromatography. Thermal gravimetric analysis and differential scanning calorimetry were performed on a Netzsch TG 209 F1 and Netzsch STA449 F3 Jupiter, respectively.

\subsection{Device fabrication and characterisation}

Glass/ITO substrates were cleaned in acetone (VWR, 99.5\% GPR RECTAPUR), isopropanol (VWR, EMPLURA), ethanol (VWR, 99.5\% AnalaR NORMAPUR ${ }^{\circledR}$ ), detergent (Hellmanex ${ }^{\circledR}$ III, $2 \mathrm{wt} \%$ water solution) and finally washed four times with deionised water. Subsequently a precursor sol yielding a $50 \mathrm{~nm}$ thick $\mathrm{TiO}_{2}$ layer was spincast according to a literature protocol. $^{52}$ The vacuum deposited bulk heterojunction was fabricated by adjusting a constant rate of $0.12 \AA \mathrm{s}^{-1}$ from the $\mathrm{C}_{60}$ source followed by evaporation of Cy3TFSI at $128{ }^{\circ} \mathrm{C}$ with a combined rate of $0.24 \AA \mathrm{s}^{-1}$. Finally after stabilization of the deposition rate the substrate shutter was opened to deposit the bulk heterojunction layer by co-evaporation. Evaporation of $\mathrm{MoO}_{3}(99.97 \%)$ as the hole transport layer and silver (99.99\%) as the top electrode followed immediately after with a deposition rate of $0.1 \AA \mathrm{s}^{-1}$. The pressure in the evaporation chamber did not exceed $6 \times 10^{-6}$ mbar during all evaporation steps. The OPV cell areas were defined as 3.1 and $7.1 \mathrm{~mm}^{2}$ by using a mask for cathode deposition. Further details about device fabrication can be found in the ESI. $\dagger$ The solar cells were characterised under an inert gas atmosphere on a calibrated solar simulator (Spectra Nova) using a Xe lamp with $100 \mathrm{~mW} \mathrm{~cm}^{-2}$ simulated AM1.5G solar irradiation. The light intensity was adjusted using a calibrated silicon reference cell from Rera Solutions. External quantum efficiency measurements were performed on a SpeQuest RR-2100.

\subsection{Further characterisation}

UV-vis spectra were measured on a Varian Cary 50. Measurement of $n$ and $k$ was performed using a spectroscopic ellipsometer M2000-VI (J. A. Woollam). The AFM analysis was performed on a scanning probe microscope Bruker Icon3 in the tapping mode. Cyclic voltammetry (CV) measurements were performed on a PGStat 30 potentiostat (Autolab) using a three cell electrode system (Au working electrode, Pt counter electrode and an $\mathrm{Ag} / \mathrm{AgCl}$ reference electrode). Single crystal diffraction patterns were recorded on a Stoe Mark II-Imaging Plate Diffractometer System (Stoe \& Cie GmbH, Darmstadt, Germany) equipped with a graphite-monochromator. Data collection was performed at $-100{ }^{\circ} \mathrm{C}$ using Mo-K $\alpha$ radiation $(\lambda=0.71073 \AA)$. The structures were solved by direct methods using the program SHELXS and 
refined by full matrix least squares on $F^{2}$ with SHELXL. ${ }^{53}$ The hydrogen atoms were included in calculated positions and treated as riding atoms using SHELXL-97 default parameters. ${ }^{53}$ All non-hydrogen atoms were refined anisotropically. All cartoons depicted in this work as well as chromophore-anion distances were prepared and measured using MERCURY CSD 3.9. ${ }^{54}$ CCDC 1834037 and 1834038 contain the supplementary crystallographic data for Cy3I and Cy3TFSI, respectively. $\dagger$ Detailed information about the background of the described experiments can be found in the ESI. $\dagger$

\section{Conflicts of interest}

There are no conflicts of interest to declare.

\section{Acknowledgements}

The use of the Scanning Probe Microscopy User Laboratory at Empa is gratefully acknowledged. We thank the Swiss National Science Foundation for financial support under grant numbers 160116 and 152909.

\section{References}

1 N. Karl, Mol. Cryst. Liq. Cryst. Incorporating Nonlinear Opt., 1989, 171, 31-51.

2 S. R. Forrest, IEEE J. Sel. Top. Quantum Electron., 2000, 6, 1072-1083.

3 D. Angmo, T. T. Larsen-Olsen, M. Jørgensen, R. R. Søndergaard and F. C. Krebs, Adv. Energy Mater., 2013, 3, 172-175.

4 M. Hösel, D. Angmo, R. R. Søndergaard, G. A. dos Reis Benatto, J. E. Carlé, M. Jørgensen and F. C. Krebs, Adv. Sci., 2014, 1, 1400002.

5 R. R. Søndergaard, M. Hösel and F. C. Krebs, J. Polym. Sci., Part B: Polym. Phys., 2013, 51, 16-34.

6 F. C. Krebs, Sol. Energy Mater. Sol. Cells, 2009, 93, 394-412.

7 H. Youn, H. J. Park and L. J. Guo, Small, 2015, 11, 2228-2246.

8 N. T. Kalyani and S. J. Dhoble, Renewable Sustainable Energy Rev., 2012, 16, 2696-2723.

9 K. Norrman, A. Ghanbari-Siahkali and N. B. Larsen, Annu. Rep. Prog. Chem., Sect. C: Phys. Chem., 2005, 101, 174.

10 D. M. Taylor, Semicond. Sci. Technol., 2015, 30, 054002.

11 H. Sasabe and J. Kido, Chem. Mater., 2011, 23, 621-630.

12 F. So, J. Kido and P. Burrows, MRS Bull., 2008, 33, 663-669.

13 C. D. Dimitrakopoulos and P. R. L. Malenfant, Adv. Mater., 2002, 14, 99-117.

14 M. A. Baldo, D. F. O'Brien, Y. You, A. Shoustikov, S. Sibley, M. E. Thompson and S. R. Forrest, Nature, 1998, 395, 151-154.

15 M. A. Baldo, S. Lamansky, P. E. Burrows, M. E. Thompson and S. R. Forrest, Appl. Phys. Lett., 1999, 75, 4.

16 J. Roncali, P. Leriche and P. Blanchard, Adv. Mater., 2014, 26, 3821-3838.
17 D. Saccone, S. Galliano, N. Barbero, P. Quagliotto, G. Viscardi and C. Barolo, Eur. J. Org. Chem., 2016, 2244-2259.

18 J. L. Bricks, A. D. Kachkovskii, Y. L. Slominskii, A. O. Gerasov and S. V. Popov, Dyes Pigm., 2015, 121, 238-255.

19 V. Z. Shirinian and A. A. Shimkin, in Heterocyclic Polymethine Dyes, ed. L. Strekowski, Springer, Berlin, Heidelberg, 2008, pp. 75-105.

20 C. H. G. Williams, Trans. - R. Soc. Edinburgh, 1856, 21, 377.

21 K. Y.-J. Liao, W.-Y. Huang, C.-L. Huang, D.-R. Chiang, D.-Y. $\mathrm{Hu}, \mathrm{A}$. T. Lee and S.-j. Ye, Preparation of cyanine dye for high density optical recording disk, US Pat. US5958087 A, 1999.

22 H. Tian and F. Meng, in Functional Dyes, ed. S.-H. Kim, Elsevier, Amsterdam, 2006, pp. 47-84.

23 J. Tan, D. Ma, X. Sun, S. Feng and C. Zhang, Dalton Trans., 2013, 42, 4337-4339.

24 H. Mustroph, M. Stollenwerk and V. Bressau, Angew. Chem., Int. Ed., 2006, 45, 2016-2035.

25 C. Shi, J. B. Wu and D. Pan, J. Biomed. Opt., 2016, 21, 050901. 26 W. Sun, S. Guo, C. Hu, J. Fan and X. Peng, Chem. Rev., 2016, 116, 7768-7817.

27 U. Lawrentz, W. Grahn, K. Lukaszuk, C. Klein, R. Wortmann, A. Feldner and D. Scherer, Chem. - Eur. J., 2002, 8, 1573-1590.

28 R. V. Markov, P. A. Chubakov, A. I. Plekhanov, Z. M. Ivanova, N. A. Orlova, T. N. Gerasimova, V. V. Shelkovnikov and J. Knoester, Nonlinear Opt., 2000, 25, 365-371.

29 M. Young, J. Suddard-Bangsund, T. J. Patrick, N. Pajares, C. J. Traverse, M. C. Barr, S. Y. Lunt and R. R. Lunt, Adv. Opt. Mater., 2016, 4, 1028-1033.

30 J. Zhang, P. J. Pellechia, J. Hayat, C. G. Hardy and C. Tang, Macromolecules, 2013, 46, 1618-1624.

31 O. Malinkiewicz, T. Grancha, A. Molina-Ontoria, A. Soriano, H. Brine and H. J. Bolink, Adv. Energy Mater., 2013, 3, 472-477.

32 A. C. Véron, H. Zhang, A. Linden, F. Nüesch, J. Heier, R. Hany and T. Geiger, Org. Lett., 2014, 16, 1044-1047.

33 G. Wicht, S. Bücheler, M. Dietrich, T. Jäger, F. Nüesch, T. Offermans, J. N. Tisserant, L. Wang, H. Zhang and R. Hany, Sol. Energy Mater. Sol. Cells, 2013, 117, 585-591.

34 J. Roncali, P. Leriche and P. Blanchard, Adv. Mater., 2014, 26, 3821-3838.

35 M. Bates and R. R. Lunt, Sustainable Energy Fuels, 2017, 1, 955-968.

36 J. Suddard-Bangsund, C. J. Traverse, M. Young, T. J. Patrick, Y. Zhao and R. R. Lunt, Adv. Energy Mater., 2016, 6, 1501659.

37 C. J. Traverse, M. Young, J. Suddard-Bangsund, T. Patrick, M. Bates, P. Chen, B. Wingate, S. Y. Lunt, A. Anctil and R. R. Lunt, Sci. Rep., 2017, 7, 16399.

38 H. Zhang, B. Niesen, E. Hack, S. Jenatsch, L. Wang, A. C. Véron, M. Makha, R. E. Schneider, Y. Arroyo, R. Hany and F. Nüesch, Org. Electron., 2016, 30, 191-199.

39 R. Hany, B. Fan, F. A. de Castro, J. Heier, W. Kylberg and F. Nüesch, Prog. Photovoltaics Res. Appl., 2011, 19, 851-857. 40 V. E. Shershov, M. A. Spitsyn, V. E. Kuznetsova, E. N. Timofeev, O. A. Ivashkina, I. S. Abramov, T. V. Nasedkina, A. S. Zasedatelev and A. V. Chudinov, Dyes Pigm., 2013, 97, 353-360. 
41 E. K. Lindenberg and G. N. Patey, J. Chem. Phys., 2015, 143, 024508.

42 D. Gesevičius, A. Neels, S. Jenatsch, E. Hack, L. Viani, S. Athanasopoulos, F. Nüesch and J. Heier, Adv. Sci., 2018, 5, 1700496.

43 D. M. Sturmer, Chemistry of Heterocyclic Compounds: Special Topics in Heterocyclic Chemistry, John Wiley \& Sons, Inc., 2008, vol. 30, pp. 441-587.

44 J. P. Armstrong, C. Hurst, R. G. Jones, P. Licence, K. R. J. Lovelock, C. J. Satterley and I. J. Villar-Garcia, Phys. Chem. Chem. Phys., 2007, 9, 982.

45 F. Heym, B. J. M. Etzold, C. Kern and A. Jess, Phys. Chem. Chem. Phys., 2010, 12, 12089.

46 J. Wei, B. H. Fan, Y. Pan, N. N. Xing, S. Q. Men, J. Tong and W. Guan, J. Chem. Thermodyn., 2016, 101, 278-284.

47 H. D. B. Jenkins, H. K. Roobottom, J. Passmore and L. Glasser, Inorg. Chem., 1999, 38, 3609-3620.

48 J. A. Venables, Introduction to Surface and Thin Film Processes, Cambridge University Press, Cambridge, 2000.
49 S. Jenatsch, R. Hany, A. C. Véron, M. Neukom, S. Züfle, A. Borgschulte, B. Ruhstaller and F. Nüesch, J. Phys. Chem. C, 2014, 118, 17036-17045.

50 J. Heier, J. Groenewold, S. Huber, F. Nüesch and R. Hany, Langmuir, 2008, 24, 7316-7322.

51 J. Heier, C. Peng, A. C. Véron, R. Hany, T. Geiger, F. A. Nüesch, M. V. G. Vismara and C. F. O. Graeff, International Society for Optics and Photonics, ed. Z. H. Kafafi, P. A. Lane and I. D. W. Samuel, 2014, vol. 9184, p. 918408.

52 P. Vivo, A. Ojanperä, J.-H. Smått, S. Sandén, S. G. Hashmi, K. Kaunisto, P. Ihalainen, M. T. Masood, R. Österbacka, P. D. Lund and H. Lemmetyinen, Org. Electron., 2017, 41, 287-293.

53 G. M. Sheldrick, Acta Crystallogr., 2008, 64, 112-122.

54 C. F. Macrae, I. J. Bruno, J. A. Chisholm, P. R. Edgington, P. Mccabe, E. Pidcock, L. Rodriguez-Monge, R. Taylor, J. Van De Streek and P. A. Wood, J. Appl. Crystallogr., 2008, 41, 466-470. 